\title{
Taxonomy of Students' Use of The iPad in Education: A Pilot
}

\author{
Liat Eyal \\ Levinsky College of Education, Tel-Aviv, Israel
}

\section{Eyaliat@gmail.com}

\begin{abstract}
This study attempts to present the variety of possible uses for iPads, in the learning process. The objective is to evaluate a unique implementation model that was tried out at a teacher training college in Israel. The methodology is based on a qualitative research paradigm. The findings show that students' use the iPads in various contexts: (a) for ongoing personal use; (b) for planning lessons; (c) for active integration in the classroom; and (d) for reading and developing content and games. These findings are summarized in a chart that shows the different uses as levels in a hierarchical taxonomy. Analysis of the iPad's pedagogical uses may shed light on the various skills students need to acquire in order to become teachers in 21 st century. In addition, understanding the various iPad uses and their frequency can affect decision-making at the level of policy in the field of implementation of the use of mobile technologies in educational institutions.
\end{abstract}

Keywords: iPads in education, integrating tablets in classroom, iPads in Teacher Training, Taxonomy

\section{Introduction}

The growing use of mobile technologies presents new challenges in the field of teacher training and classroom instruction. Mobile technologies include smart phones, laptop computers, electronic reading devices, and tablets - all of which are easy to carry and connect to the internet.

A review of literature indicates that the field of mobile learning encompasses a variety of terms, each of which reflects a different perspective. These terms include m-learning, mobile learning, ubiquitous learning, and handheld learning.

The review of literature shows that mobile learning has yet to be defined unequivocally. One of the accepted definitions is "any type of learning that takes place in learning environments and spaces that take account of the mobility of technology, mobility of learners, and mobility of learning" (El-Hussein \& Cronje, 2010, p. 20). Other researchers address the different uses of mobile

Material published as part of this publication, either on-line or in print, is copyrighted by the Informing Science Institute. Permission to make digital or paper copy of part or all of these works for personal or classroom use is granted without fee provided that the copies are not made or distributed for profit or commercial advantage AND that copies 1) bear this notice in full and 2) give the full citation on the first page. It is permissible to abstract these works so long as credit is given. To copy in all other cases or to republish or to post on a server or to redistribute to lists requires specific permission and payment of a fee. Contact Publisher@InformingScience.org to request redistribution permission. technology, such as support for the learners and their participation in creative, cooperative, critical, and communicative learning activities (Cobcroft, Towers, \& Smith, 2006).

Traxler $(2007,2010)$ suggests that mobile learning is intended to provide support for authentic and personal learning processes, is situation-dependent, and that in the future mobile learning will 
enable a wide range of learning methods. Rossing, Miller, Cecil, and Stamper (2012) define mobile learning as the most effective use of digital and wireless technology in empowering the learning.

In summary, the distinguishing factor between mobile learning and other learning methods supported by technology, including e-learning, lies in the way that learning experience is mediated and enabled (Peters, 2009). The learning process takes place in a situational context and is affected by the interaction between the learner and the technology used individualy or/and in cooperation with others (Melhuish \& Falloon, 2010).

\section{Mobile Device Types}

A wide range of devices are classified as mobile technology, with the term mobile reflecting the ability to move from place to place, or from situation to situation. Mobile technologies can be classified on a continuum from regular or static use to the full range between personal use to collaborative use (Naismith, Sharples, Vavoula, \& Lonsdale, 2004).

The first group of technologies is characterized by mobility and personal use. These are the most common technologies such as mobile phones, PDAs, tablets, and laptops. These technologies also include hand-held video game consoles, the use of which has been reported in the context of learning (Lee, Luchini, Michael, Norris, \& Soloway, 2004; Rosas et al., 2003). Because these technologies are usually for a single user, they are perceived as personal devices. The online nature of these devices allows communication and information sharing. Thus, while the devices themselves are personal, it is easy to share the information and content they contain. In addition, these devices are classified as mobile because you can move them from place to place, and because they are available for use in different locations (Naismith et al., 2004).

A second group of technologies is characterized by less mobility, but still enabling personal interaction, for example, the various remote control devices (like Clickers) handed out to students for the completion of multiple choice tasks and questionnaires.

A third group of technologies enables greater interaction, but less mobility. This group includes smart boards and video conferencing capabilities. It should be noted that these technologies are viewed as static in principle, thus they do not comply with the accepted definition of mobile technology. However, this classification is important to an understanding of the catalog of technologies presented above (Naismith et al., 2004.).

A fourth group of technologies enables the sharing of information and availability in different places. At the same time, the technologies themselves are not necessarily mobile. For example, they can be computer work stations in the work place, interactive displays in museums, and other facilities where the devices provide access to knowledge and its dissemination. In these cases, the technology is not itself mobile; it is the learner that is in movement. Larger screens enable simultaneous use by multiple users (Naismith et al., 2004.).

\section{Potential of Mobile Technologies}

Mobile technology offers several advantages in the educational context (The separation is for emphasis, but there is a close link and mutual influence):

Access to learning anywhere, anytime, without the need for extra resources - In today's schools, a transition is taking place from computer laboratories to the use of laptop computers and other hand-held devices (Johnson, Levine, Smith, \& Stone, 2010). The relatively small size and weight of mobile technologies make them easy to transport from place to place - a clear advantage. An added advantage lies in the ability to use this "invisible" technology in the learning process and its potential for facilitating interaction and collaboration between the learners. 
The smart phone is indeed the most convenient technology for mobility and creating asynchronous communication between learners, but the tablet offers added value due to the relatively low cost of computing power offered. It seems that learners are more comfortable using a tablet when working in groups than using a laptop or smart phone, mostly due to the larger screen size and ease of transfer from hand to hand (Melhuish \& Falloon, 2010). Moreover, the mobility of the tablet allows learners to take it outside of the classroom, for "field work", such as transferring electronic documents and books, recording observations, accessing information sources, and more (Johnson et al., 2010). These characteristics contribute to the tablet's ability to offer learners greater convenience and availability than other mobile devices (Melhuish \& Falloon, 2010).

Learning that has an environmental impact - The potential of mobile learning lies not only in the technological advantages listed above. This type of learning has an impact on the values of the physical and virtual environment. It can be more situational, personal, collaborative, or lifelong (Naismith et al., 2004).

Informal learning enables constructivist teaching - The use of a tablet allows informal learning suitable to the learner's existing knowledge and frame of reference. These characteristics might enable the advancement of constructivist methods in education, in the framework of which teachers function as facilitators (Mouza, 2008). This way, you can learn within the situational context through ongoing dialogs with colleagues, in support of the social constructivist learning approach - an approach that we encourage in teacher training with the goal of seeing it implemented both in classrooms where student-teachers gain practical experience, and with their pupils in the future. The construction of knowledge takes place through collaboration. The learner's extensive autonomy will enhance the learner's meta-cognitive abilities and make it possible to consider complex and authentic problems in the practice environment in real time (Herrington, Mantei, Herrington, Olney \& Ferry, 2008). Mobile technology enables learners to share and create knowledge, and become acquainted with a wide variety of content and persons anywhere and anytime (Dew, 2010).

Development of interpersonal and social ties - Different mobile applications enable the learner to create, share, and connect with others within the context of authentic learning and to participate in online learning communities. This can be done, for example, over wireless networks or using Bluetooth technologies, though these require infrastructure and technical support. An effective mobile learning environment requires a robust institutional infrastructure, which will expand the range of relevant resources and provide the necessary technological and financial support (Melhuish \& Falloon, 2010).

Personal, individual learning experience - The tablet is a device that is used by a single user, although a tablet can be shared between users or used for collaboration. The learner can choose which applications to use and adapt them to meet their needs and goals.

Support for the development of visual and textual literacy - The tablet enables learners to take a photograph and immediately upload it to the Internet, edit videos easily, and use applications that teach languages, math, problem-solving and strategy games, drawing tools, as well as learning aids such as spoken texts (Kelly \& Schrape, 2010; Valentino, 2010). These endless possibilities make the tablet a powerful tool for teachers and learners alike.

However, as with any technology, the use of mobile technology in learning is not without its limitations. There are technological limitations, for example, the relatively small screen size, which might not suit all learners. There are also issues related to lapses in internet connectivity (Alexander, 2004), limited memory size, and the need to frequently recharge the battery (Georgiev, Georgieva, \& Smrikarov, 2004). There are also obstacles related to socio-economic factors, for example, the fact that not all learners are able to purchase the device. Nonetheless, in my opinion, the more pointed questions related to the use of mobile device center around its educational and 
pedagogical contribution to learning, and the relationship between educational processes and the technological environment.

Teachers who employ technology need to be aware of its advantages and disadvantages, and be proficient in its use. This is to mediate its use for the learners and make the learning process as effective as possible (Melhuish \& Falloon, 2010).

\section{Models for Tablet Use in Education}

There are those who maintain that learning in itself does not change, it is only the mode of learning that changes. In this respect, tablets are a mean for advancing empowerment processes. This approach is reflected in the 3-E education model - Enabling, Engaging and Empowering (SpeakUp 2010, 2011, p. 3). According to this model, teachers need to recognize that learning has to enable learners to reach their potential though increased access to information sources; engage learners in a rich and challenging educational experience, that will develop their knowledge and skills, especially through problem solving, creativity, and critical thinking; and empower learners to take responsibility for the learning process, to explore knowledge and their own creativity, and create live long learners (SpeakUp 2010, 2011, p. 3).

A different model for the use of mobile learning integrates number components, including, first and foremost, the learner and the teacher-facilitator. Technology enables educators to design and develop interactive learning activities. When presented with these activities, the learner can take full advantage of the tool and use it to explore the available knowledge (Monahan, McArdle \& Bertolotto, 2008; Price \& Rogers, 2004). For example, the learner can access information anytime and anywhere, without extra effort. Because you can document the mobile learning process, the teacher-facilitator can gather information from the technology used by the learner. The facilitator can guide the learner to additional sources of information as needed, and present learning materials appropriate to the learner's current stage in the learning process. The learner receives feedback during the process, enabling individualized study and optimal adaptation to the learner's needs. The role of the facilitator is to monitor the needs of the learner and provide the necessary support (Jeng, Wu, Huang, Tan, \& Yang, 2010).

The improvement of learning processes is also a component of the mobile learning model. This can be accomplished using various tools such as a blog that features informative articles that help advance the learning process. Blogs can be used to collect data and information, and as a platform for shared learning (Wang, Huang, Jeng, \& Wang, 2008). In addition, you can enhance the learning process through the development of applications designed to support learners and which serve as a kind of coach or support to help the learner through the process, with their presence gradually reduced as they become less necessary (G. D. Chen, Chang, \& Wang, 2008; Y. S. Chen, Kao, \& Sheu, 2003).

Another component of the mobile learning model is the situation-based learning environment. For example, you can use the functions of sensors that are found in mobile technology to locate and identify factors in the learning environment. You can create a simulated environment for the learner and allow him to practice under conditions that are closest to the real situation (Yang, 2006).

The last component in the model is the development of virtual group awareness and strategies. Various studies describe the benefits of using mobile technologies as a group (Zurita et al., 2005). The group dynamic methodology can be applied to learning activities that require cooperation. Virtual group membership might strengthen the learner's involvement in the material studied.

Other researchers focus on the unique potential of tablet devices that might be developed in specific fields. Eagleton and Dobler (2007) examined how the use of tablet devices impacts on teach- 
ing and learning in the context of reading. In their opinion, the use of digital books creates an opportunity for the development of literacy. Digital books are available on tablets and offer advantages in that they allow the readers to interact with the text and at the same time manipulate it based on their needs. In this way, the reading experience becomes individual, interactive and involved (Larson, 2010). In addition, the tablet includes apps that are free or relatively inexpensive and which promote reading skills such as reading, taking notes and commenting on the text, adding images and symbols, graphic organization of text, and even sharing text and working on it together with a colleague (Hutchison, Beschorner, \& Schmidt-Crawford, 2012).

\section{Tablets in the Israeli Educational System}

Recognizing the power of learning using tablet devices, tablets have been purchased in schools in Israel and around the world. There are abundant examples; however, the author will relate in particular to innovative initiatives for tablet integration in education in Israel, because the range of available Hebrew educational applications is relatively limited.

One of the most innovative initiatives was implemented by the AMIT Educational Network. AMIT integrates learning with tablets using a newly developed Israeli technology platform called AURA. AURA is designed to enable learners and teachers to conduct ongoing private dialogues, and it has been adapted to the pedagogical approach in the schools. Since the introduction of tablets, it has been found that teachers spend less time in class on each topic because the pupils have used the tablet to practice/review the material in advance. This makes it possible to maintain the social heterogeneity of the class, without holding back stronger students because of their weaker classmates.

Another educational network, AMAL, initiated a wide-scale pilot project for the use of iPads in technological studies (new media, Mechatronics). In addition, in one high school that was fully equipped with iPads, the tablets were used for project-based learning (PBL). AMAL also developed a unique curricula for the study of Augmented Reality technology, which enables the interactive integration of virtual elements in the real environment, in real-time.

One of the most impressive projects uses iPads for place based learning. The project is a digital tourism project based on augmented reality, in which teenagers have developed a tourist route at the 'Sarona' Tel Aviv compound, containing historic buildings that have been renovated and has recently become a leisure and entertainment complex with a rich heritage. The pupils were divided into working groups, each of which built several stations located on the route. They studied and interviewed key personnel for the production of historical videos to illustrate the route. Accessibility was a main concern in the creation of the route. It was examined in collaboration with special education pupils from a nearby school. QR code landmarks were placed on the trail, so that each visitor can inspect the route through an application, get the relevant information and follow the leads. The project serves as a contribution to the community and as a public service.

There are also localized initiatives for the integration of tablets in elementary schools throughout Israel: Three elementary schools in Pardes Hanna-Karkur switched from printed books to digital books during the last year (2014-2015). This project is part of the national program "Adapting the education system to the 21 st century," which brings together all of the community's elementary schools, with the support of the local council, to invest in the infrastructure necessary for the program's implementation - a projector in each classroom, internet connectivity, and laptops for teachers. These schools will no longer have only print versions of the textbooks; digital versions will become available as well. At the first stage, language, science, geography, social studies, and some of the math books were converted into digital format. Later on, all of the text books were converted to this format. 
Bat-Yam municipality also decided to provide all seventh graders with iPad devices, with the participation of parents. These will replace traditional textbooks. Since the socio-economic level of this city is not high, parents protested regarding the heavy financial costs imposed on them. Studies on the educational value of this project have yet to be presented.

One of the most promising areas in which the use of tablets is particularly prevalent is in special education frameworks in Israel. The Ministry of Education initiated special projects where entire classes of learners with special needs and their teachers use iPads in the learning process. Some of these initiatives have been accompanied by research; it appears that the effectiveness of the use of iPads among learners with communication-related disabilities is particularly high.

\section{Technology in Teacher Education Programs}

Vast resources are invested in the implementation of tablets and in training teachers on their intelligent use in the learning process in the schools. Implementation is carried out on various levels, ranging from the technical level - usually there is a technical support system for the municipality or the supervisory body - to the didactic level - with national computerization facilitators regularly visiting the schools to guide the teachers in the integration of the new technology. Researchers from academia also volunteer to help in the implementation process and advise school principals regarding educational pedagogical processes and the like. Nonetheless, these assimilation processes do not guarantee the success of these initiatives to integrate the tablet. There are studies that indicate that, despite the dedicated work of teachers, there is no relationship between the new media and the teaching and learning methods. The integration of mobile devices has not brought with it a corresponding change in teaching methods and didactic operating strategies. Teaching remains traditional. Another reason for the lack of success of such initiatives is that teachers are not always given the freedom of operation needed to create linkage between the curriculum and the learning spaces adapted to integrate this technology (Shamir-Inbal \& Blau, 2013).

Studies show that intervention should be based on training that helps teachers to acquire competency in the technological tools, as well as experience in applying new pedagogical ideas in order to understand the relationship between pedagogy and technology (Eyal, 2012; Fishman, Best, Marx, \& Tal, 2001). Therefore, to prepare future teachers for a better start in their first year of teaching, especially in those schools equipped with the technology, there is room to consider the implementation of tablets in the teacher training process, similar to the implementation of computerized communication processes in colleges of education in the context of stationary and laptop computers, Although technology courses have not been prioritized in teacher preparation programs, Betrus' (2012) study noted that the number of institutions offering an introductory technology course for teacher education students decreased from $80 \%$ in 2000 to $64 \%$ in 2010 . The same study also noted that while more than half of the topics taught had changed over the ten year period, the emphasis remained on office applications rather than emerging technology.

Studies indicate that the mastery of different technology skills is not a function of age, instead differences are related to experience with technology (Eshet-Alkalai \& Chajut, 2010).

For instance, a case study at University of Southampton Management School (Morrison, 2014) assessed the staff and student perspectives trying embedding the iPad as learning and teaching tool. Staff and students on the Master of Business Administration (MBA) program were provided with an iPad at the beginning of the 2013-2014 academic year. The results of initial research indicate that while the overall reaction was positive, acknowledging the benefits of 'new' technology or different ways of teaching and learning, there are also barriers to uptake or use. Students used the iPads quite extensively in the first week and indicated that they had underestimated the potential of the iPad as a learning tool. Staff also explicitly stated that they saw considerable potential 
in iPad use in their teaching and were happy to trial new technology. There was a clear preference for more support in their use, even from experienced technology users.

A relevant study at the Pennsylvania State University in USA by Tohill (2014) examined preservice teachers' experiences with iPads during their student teaching experiences and supported previous research studies that suggest technology education must be an integral part of teacher preparation programs in an effort to improve teaching and learning with modern digital tools. Teacher preparation programs must continue to encourage pre-service teachers to innovate and explore with technology in ways that support both personal and professional development and that improve learning experiences for students.

\section{The Research}

The research under discussion studied a pilot program at an Israeli teacher training college, in the framework of which tablet devices were loaned to the students. The subjects were 18 students from the pilot group who were studying in the college's honors program in a variety of specializations, for example, special education, early childhood education, mathematics instruction, English instruction, science instruction, and so on. The students in the honors program have relatively high levels of academic achievement, and approximately a third of their curriculum is unique and customized. The students received the tablets in their first year studies (except two who were in their second year), and the tables were in their possession for two years.

Unlike an existing implementation sample of this pilot, this study examines the ways students' use the tablets based on an implementation model that does not include training, pedagogical guidance, or support from an ICT faculty expert. The students were given the freedom to use the devices as they saw fit. They were given the possibility of consulting with an expert on the integration of advanced technologies in education, on both the technical and pedagogical levels. Some students also enrolled in elective courses that address the integration of technology in education.

The objective of this study was to examine and characterize students' use of tablets on two levels: 1) the general and personal level; 2) as a pedagogical device in the classrooms, in order to evaluate the success of the implementation model where the extent of intervention is particularly low.

\section{Research Questions}

The research questions were:

A. How do education students use the iPads?

B. What pedagogical uses of the iPads did the education students implement to advance the learning process?

C. What model can be proposed for using iPads based on the students' uses (both personal and pedagogical)?

\section{Research Method}

The study was conducted based on a qualitative research paradigm based on the approach of the construction of a grounded theory. This genre of research focuses on the study of a phenomenon from the perspective of the informants, while the accompaniment of a theoretical analysis based on the interpretation and comparison of literature and analysis with existing theories (Charmaz, 2000).

Data were collected from a variety of research tools and were cross-referenced (triangulation). The research tools included semi-structured personal and group interviews, online questionnaires 
in Google docs, students' reflective performance reports, lesson plans, observations of practical experience at schools, and documentation of discourse on social media.

The unit of analysis was a statement (e.g., from a reflective performance report or social network) or a description (e.g., from a questionnaire or a record of observation) indicating use of the iPad. Each unit of analysis was coded and received a representative name (primary categories), reflecting the students' prominent uses of the device the subjects' language (emic). The data was then sorted accordingly (the axial and directed coding phase). After determining the first primary categories, the units were then organized into secondary and tertiary categories, and the category names were updated based on existing literature, creating a hierarchy of categories. The number of units in each category was counted to gain a sense of the frequency of each type of device use.

The resulting model was consolidated by linking the findings and the theoretical literature about the pedagogical uses of iPad devices, and this enabled broader conclusions to be drawn, which are presented in a graphical model.

\section{Findings}

\section{A. How do education students use the iPads?}

The findings reflected the following division:

- $63 \%$ of the students made extensive use of the iPad

- $\quad 27 \%$ of the students made very little use of the device, and at the end of the semester they were asked to return it. The devices returned were then loaned to different students.

The reasons that students cited for making minimal use of the device included the following: inadequate technological literacy; they did not see its value in classroom teaching; or many of the same applications are found on their smart phones, making the use of the iPad redundant.

The findings show that the students' primary uses for the iPad were (a) for ongoing personal use, (b) for planning lessons, (c) for active integration in the classroom, and (d) for creating and developing content and games.

\section{Ongoing personal needs}

Students incorporated the iPad in their day-to-day routine at home or at college, for both personal and academic purposes. Common uses included calendar and schedule management, reminders, photography, drawing, scanning materials, documentation, recording, and getting information from newspaper articles and books.

"As a student who spends most of my time at the college, doing my practicum, at work, or on the road, the iPad helps me in my daily routine. I use it as a notebook, film activities that I implement (one of its best things for me), read articles, and write papers. The iPad helps me be more efficient and meet deadlines in the busy life I currently lead." (From the online questionnaire)

In this respect, students claim that the device is comfortable to use and easy to carry, therefore it can be taken anywhere, making it possible to take advantage of free time.

In addition, it is commonly used for recording college lectures, taking notes lists and summarizing lessons:

"I have an app that creates a kind of notebook for each lesson, even the notes I take are sorted according to subject." 
Although the students mentioned that the iPad is not a particularly comfortable tool for editing complex documents, some students indicated they use it for writing drafts, making use of different applications that allow the editing of texts. Students also noted that the device saves them on printing and photography costs, because they use it to photocopy articles and academic information items.

\section{Planning and instructional design}

The second category of iPad use includes self-learning related to the student's specialization, locating information, and reading relevant academic articles and books. In addition, as part of their studies at the teacher's college, students gain practical experience as student-teachers in schools and kindergartens. As part of the learning strategy, students are required to document themselves teaching in the classroom. Use of the iPad enables the students to view the recording multiple times, reflect on the their teaching encounters in the classroom or kindergarten, draw conclusions regarding their performance for the purpose of better planning, revising, and improving their teaching in the future.

The use of the iPads by students also created a ripple effect, impacting on how the pedagogic counsellors monitor and guide the students in the practicum. One of the teachers asked students to video record the lessons given in class and then to describe their experience to their classmates, instead of the traditionally submitted written reports. Most students said that they used the iPad in the lessons planning process, especially when they are traveling. In addition, students used the device to locate applications and unique materials for teaching specific subject matter and to find ideas on how to implement those materials in the classroom.

\section{B. What Pedagogical Uses of the iPads did the Education Students Implement to Advance the Learning Process?}

As part of the practicum, students integrated the tablet into the teaching and learning process in a variety of ways. Observations and lesson plans show that the main uses identified are the following.

\section{1) Enhancement of frontal teaching}

By connecting the iPad to a projector, students used the device to display presentations, website, or games).

For example: Figure 1 shows a simulation of the microscopy separation principle (i.e., how the microscope works). The tablet captures the skin and gives a sense of how it zooms in, demonstrating the difference between the magnified size and the regular size, and the microscopes role in separating objects. 

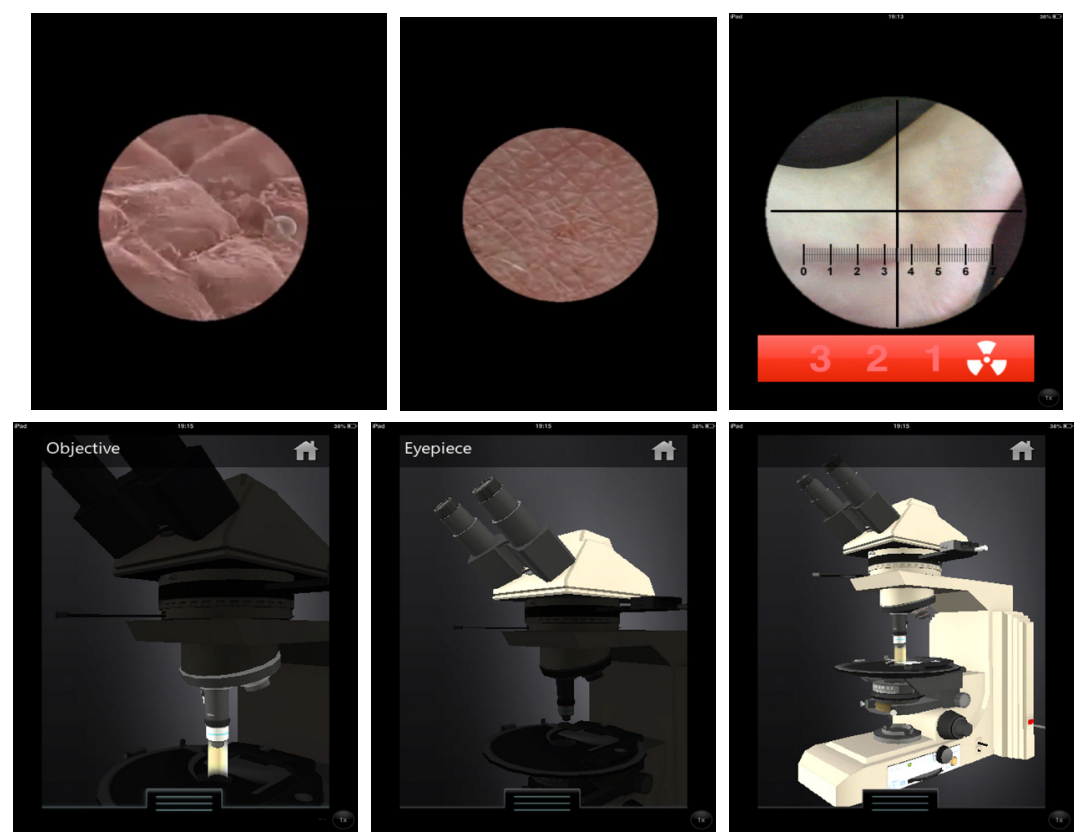

Figure 1. Screenshots of an application simulating a microscope

Pupils in the classroom were shown the microscope simulation and its parts were explained. According to a student specializing in science instruction, the added value of the application lay in solving the problem of excess stimuli that occurs when microscopes are placed on the pupils' desks. The application demonstrated the principle of separation in a clear and interesting way, providing an authentic sense of true magnification. The demonstration was accompanied by a theoretical explanation, given by the teacher, and provided the linkage to reality. In this context, the use of the tablet is more effective than a presentation or a teacher's hands-on demonstration of the microscope, when not all 35 pupils are able to use it. In addition, pupils used their mobile phones to photograph what they saw under the microscope (as observed by teacher Y.)

\section{2) Teaching in groups}

Another example is that of students in the early children education program, who used the tablet in the kindergartens. The necessary technologies for presenting computerized visual content are not always available. Future kindergarten teachers indicated that they used the device primarily to show clips to young children, followed by a discussion of what they saw. The clips were selected based on the subjects being taught in the kindergartens.

\section{3) Active learning - Integration of dedicated applications}

Lessons that integrated applications dedicated to the students' area of specialization, where the learners use the device as individuals or in groups. The integration was implemented in one of two ways: free use of an application that focused on a subject or skills, without guidance from the teacher; or by assigning defined tasks to the learners.

For example, Figure 2 shows the use of an application in the framework of English instruction. The application enables the learner to highlight text, cut it, and copy it. 
A

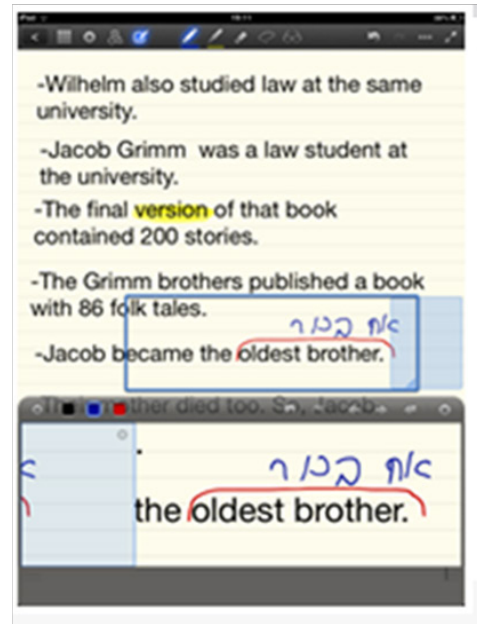

B

-Wilhelm also studied law at the same
university.
-Jacob Grimm was a law student at
the university.
-The final version of that book
contained 200 stories.
-The Grimm brothers published a book
with 86 folk tales.
.-Their mother died to.. So, Jacob
worked at the library to support his...
-Jacob became the oldest brother.

C

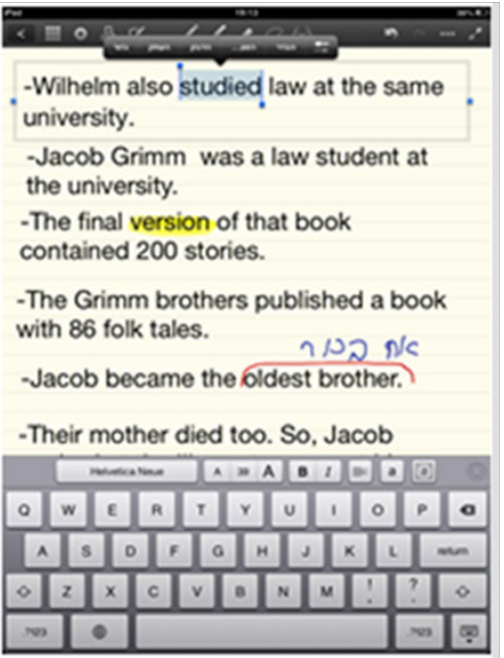

Figure 2. Working with Texts: (A) Highlighting text, enlarging select areas, and adding handwritten comments; (B) Cutting and moving text; (C) Editing text, copying words

The application enables the learner to highlight text, cut it, and copy it. In addition, the Google translate application was used.

The pupils worked in groups of three, and each group was given a different sentence. First, the pupils needed to arrange the sentences in logical chronological order (A). Then they cut and moved the sentence (B). When the first team finished, they were given an additional task - to copy all the verbs (C). They copied the text to a new page, where they processed and analyzed the verbs (translating, highlighting tense indicators, and so on).

The student teaching English in the class describes the added value of using the table in this activity:

The activity created interest and motivated the pupils, time was saved (no need to copy words, cut pages, etc.), it was possible to focus on and analyze the original texts, highlighting words it contained, and assigning additional tasks that would not be feasible on paper (because of the ease in copying and duplicating text). (B. reflective diary, Oct 15, 2012)

Students used specialized applications for teaching math, writing, and drawing as part of the group tasks. They also used gaming applications, for example, an application that simulates an aquarium where you see the movement of the water.

Students indicated that they created databases of applications and users on a dedicated social network set up for the sharing of tools that they had tried out and found successful. They also noted that in many instances they used the device as an education tool beyond the content-based educational objectives. For example, one of the science student-teachers who was teaching about the states of matter asked the pupils to draw gas particles. After the drawing was photographed using the tablet, it was projected on to a screen, for the entire class to discuss. In this way, she strengthened students' self-confidence and belief in their own capabilities:

Games on the iPad are also served as a tool for reinforcement (children are eager to play with the device) and as a means of learning - with my choice of games for their use based on their overall and educational quality. In the special kindergarten, the children particularly like the game Awesome Eats - which combines fine motor skills with an under- 
standing of the process of a healthy diet of fruits and vegetables. In a great game for naming, matching and sequencing skills, SpeakApp (the version that you can buy), children can record themselves and create new events. (D. reflective diary, Jan 23, 2012)

In one of the lessons that the author observed, the student-teacher planned activities for teaching English using the tablet in a group of four students. During the activity there were many disruptions, the students fought over the device, shouted and treated one another disrespectfully. The student-teacher threatened to take away the device and the next time to invite another group to work. In a feedback conversation, the student-teacher realized that the she needed to determine explicit rules and norms of behavior. She set a goal to establish a relationship of mutual respect between pupils in subsequent lessons. Through her experience in using the device in the class, the student learned some of the skills necessary to for optimal classroom management.

\section{4) Media stimuli or media support}

A special education student-teacher indicated that the device has important advantages in the area of media support. In one of the lessons the author observed, the tablet helped a learning disabled pupil who was integrated into a mainstream classroom to express her feelings and take an active part in the language lesson.

The pupil used the tablet to express her joy and excitement at being part of an integrated classroom and displayed a smiley to all of her friends (from observation of A.'s lesson on Nov 12, 2012). While younger students learned about different animals, the student-teacher helped the pupil to find a picture of a chicken. She learned to write the word with help from the studentteacher, who guided her finger through the process. She moved among her classmates, proudly pointing out the picture and the caption above it. She moved among the tables and received reinforcement from her classmates.

Other special education pupils used the table to create cards that express emotions (not at all like the traditional cards). The tablet expanded the pupils' communication options, assisted by the student-teachers who worked with them.

In her reflective report, one student wrote:

I also use the application 'ShowMe' to edit and paste photos. I have already taken lots of pictures during lessons. It ties the girl to the language aspect of the words because fine motor skills are problematic. Now the motor skills are less of a problem, before the iPad there was nothing she could do when the class worked on the questions and wrote with a pencil. As soon as she felt that she herself can write the name with the picture, she also participates in the lesson. With mental retardation illustration is important. The picture in the book was a drawing of a chicken, and it was important to show her a real chicken to link it to reality. The iPad empowers the pupil and raises her to a higher level. It also strengthens her social ties with her classmates. (G. reflective diary, Apr 20, 2012)

\section{5) Motivational tools}

According to students' reports, the tablet also serves as a means of motivation and strengthens communication between them and their students. For example, one student reported that in order to increase learning motivation, she promised a pupil that she could choose a game on the device, and that she would play it with after he completed the assigned task. Students used it for activities that the pupils like to participate in, and they utilize them in the learning process. Another example is taking pictures of the children at play and during creative activities. They noted that this use often serves as form of positive reinforcement to promote creativity. The children love to take pictures and be photographed, including while putting on plays/drama presentations. 


\section{What Model Can Be Proposed for using iPads Based on the Students' Uses (Both Personal and Pedagogical)?}

\section{6) Creating and developing content and games}

Although this use of the tablet could be included in the category of integration of the tablet in the active learning, the author chose to treat it as a separate category to emphasize the difference between using existing applications (closed or open), and the development and creation processes, for which not all students have the necessary capabilities or interest. This category refers to the development of games using dedicated platforms that enable the teacher to insert the relevant content matter into some genre of games. A limited number of students participating in the study developed tutorial or other educational and social games for use outside the classroom.

For example, students specializing in early childhood education developed games to use in their practicums in the kindergarten. The students used the 'TinyTap' platform to create these games. The game they developed allowed them to take a personalized approach, to adapt the learning content to individual educational programs, to adapt the level of the game to the cognitive skills of the learner, and to provide appropriate reinforcement according to the emotional and learning needs of the child, all through the use of an attractive and stimulating visual display, as shown in Figure 3.

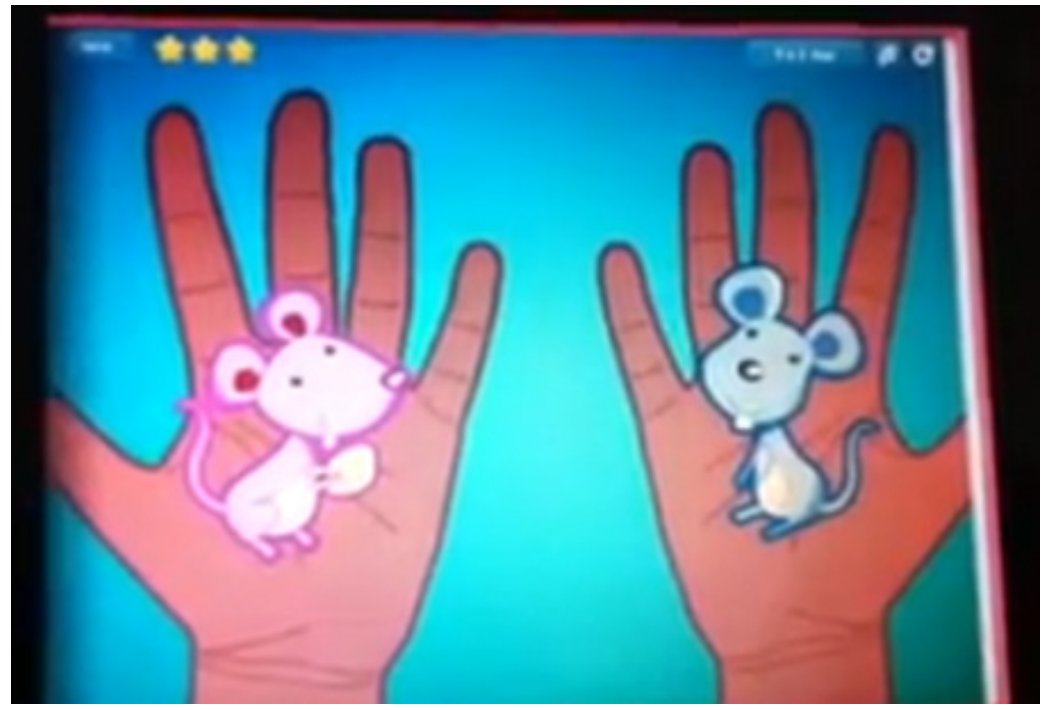

Figure 3. Screenshot from a game for preschool children developed by students

In their reflective reports, students indicated that the children enjoyed using the tablets during the session; it captured their attention, they were excited by the immediate stimuli and the immediate reactions they aroused in them. In individual learning, where the objective was to teach didactic content, especially when working with special needs children, it is highly advisable to approach the material in an experiential way that helps the learner concentrate and take an active part in the learning.

Another student used the games as a platform for creating games as an activity in and of itself, for example in the teaching of English. She presented an overview of the platform and gave the pupils an opportunity to create a game based on new and difficult vocabulary that they had not previously encountered in the text. The pupils prepared games in groups, which were then played by their peers from other groups. 


\section{Discussion and Conclusions}

A review of the findings about the students' uses of the tablet in various contexts shows that they are similar to findings of other researchers; the students took advantage of the device's inherent range of possibilities and technological opportunities: mobility - access to information and learning anywhere and anytime, time management and organization of information, photography and editing options, and integration of applications in the study of various subjects (Dew, 2010; Johnson et al., 2010; Kelly \& Schrape, 2010; Melhuish \& Falloon, 2010; Valentino, 2010).

In addition, students integrated the use of the device in the teaching and learning processes in classrooms, in working in groups, while promoting constructivist learning methods, while the learners gain experience, research and read information, watch simulations and discover the patterns in the course of the game and dialogue with their peers. This finding corresponds to the viewpoints of other researchers who treated the tablet as a tool that enables learners to be engaged in challenging, creative, and collaborative experiential learning (Herrington et al., 2008; Mouza, 2008).

There was a change not only in the quality of teaching in the classroom, but also in the students' outlook on their future professional development. The development of learning materials in the form of computerized games is not a routine activity for teachers. For the most part, it is time consuming, and requires high level planning and thinking, and design skills. When the students developed the material, they each brought their own unique talents - academic and professional to a high level of expression; they had a better understanding of the material being studied, greater preparedness for the teaching process, and greater satisfaction. The empowerment of learners was especially reflected when students used the tablet as a means for improving and supporting communication with students.

Observations of the education students in the classroom showed that the students most often used the tablet in the context of more traditional teaching, based on the frontal transfer of knowledge. At the same time, in lessons where the tablets were placed in the pupils' hands, the students demonstrated guidance strategies, providing support for the learners, and engaging the learners in collaborative learning and dialogue. The very presence of the device in the learners' hands created a change in the students' perception of their role as teachers. They planned their lessons in advance, acting as mentors and coaches in their implementation. This finding is also supported by other studies (G. D. Chen et al., 2008; Y. S. Chen et al., 2003; Jeng, Wu, Huang, Tan, \& Yang, 2010).

In the unique implementation model tested in this study, students did not receive pedagogical support for planning and implementing lessons using the device. Still, it seemed that the more they experienced they gained in school with the device, the more sophisticated and creative the lessons they developed became, to the point where they created open use of creative learning materials, simulation, and games. The user friendliness of the device and its intuitive interface require almost no special training.

This finding is consistent with the findings of the researchers who suggest a link between the duration of experience and the degree of control of the device (Eshet-Alkalai \& Chajut, 2010). However, this finding contradicts the findings of other studies that maintain that there is need for a training program to acquire the technology skills for establishing and implementing innovative pedagogy.

Either way, the findings of this study can't be generalized, due to the fact that there is no data on those students in this research population who chose to return the device. In addition, the group of students was relatively small, with unique characteristics (students at excellence program). It is important to emphasize that in order to develop the students' understanding of the innovative 
pedagogies, which they acquire as they gain experience, and their ability to engage in reflective thought, the role of the reflective dialog between the pedagogical coach, the teacher-facilitator, and the student-teacher is important. In this study, reflective thinking was made possible through interviews and reports submitted as part of the study. Some of the dialogue could take place on a social network, such as the one established for that purpose in this study. Social networks provide opportunities for open, accessible, and dynamic discussion, creating interaction between students at different points in the experience for the exchange of knowledge and opinions, and sharing applications reading materials.

Linking between the findings of this study and the findings of the theoretical literature on the pedagogical uses of iPad devices made it possible to formulate a model (Research Question 3) based on the principles shown in Figure 4. Figure 4 presents the overall uses of the iPad, as reflected both in the literature and in this study.

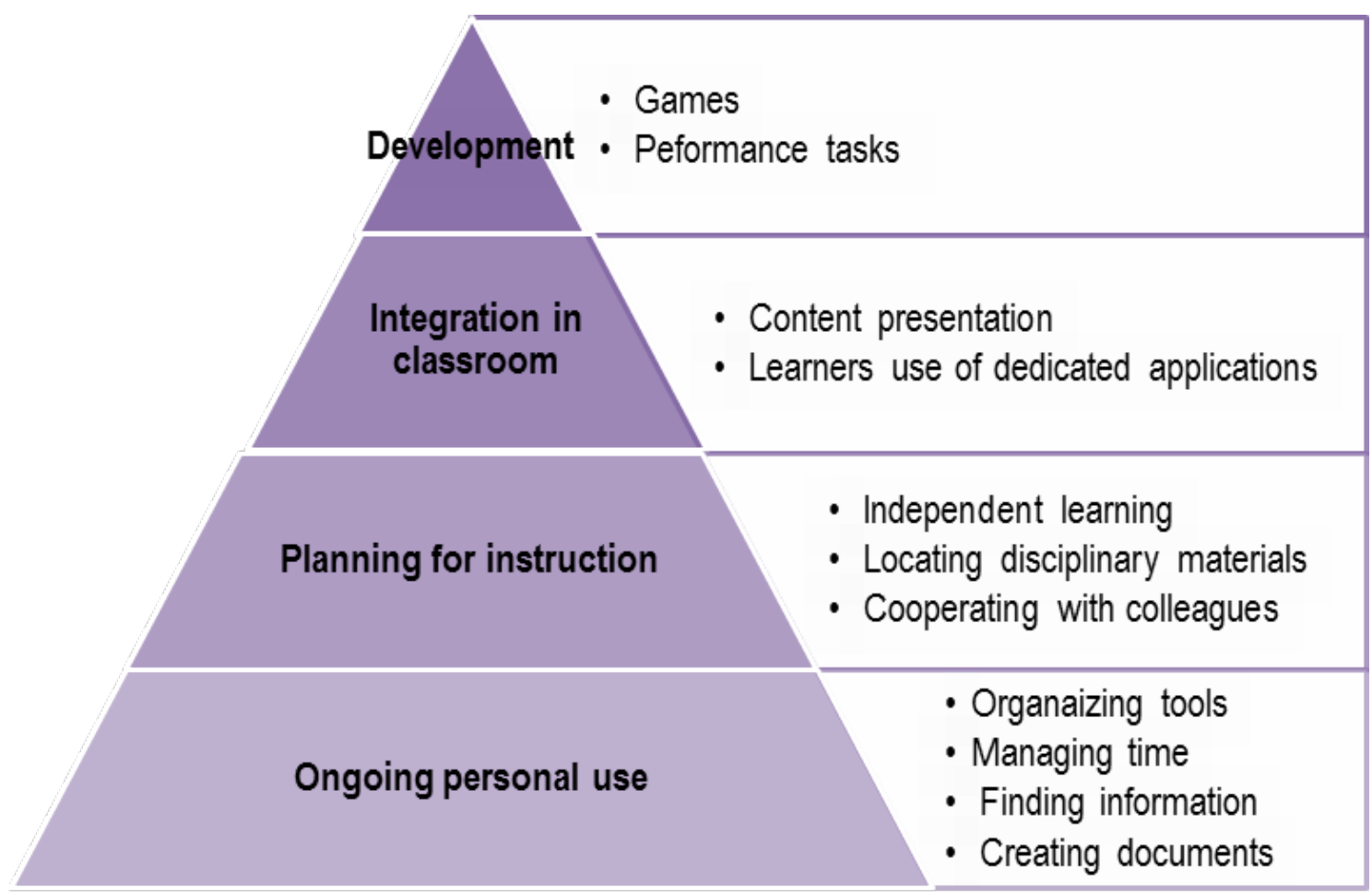

Figure 4. Taxonomy of students' use of the iPad in education

This chart presents the different uses as levels in a hierarchical taxonomy. Taxonomy is a hierarchical classification of things or concepts. Each level in the diagram includes the levels below it. The principle is that the greater the knowledge and experience of students, the more sophisticated is their use of the device.

The process of acquiring the skills of using iPads in teaching reveals different levels of use. The first two levels at the bottom of the pyramid represent basic uses: A) Personal Uses: Creating documents and lists, consuming information, calendar management, summaries of lessons, and recordings, and B) Instructional Design - including instructional context uses, locating disciplinary articles as part of curriculum development, self-learning, and communication with colleagues. Two higher levels of integration of iPads in teaching include $\mathrm{C}$ ) Integration in the classroom - for the purposes of displaying content up to the level of constructive learning, for example, a group of pupils working together and using relevant applications. The highest level, D) Development, includes games development and planning performance tasks using open platforms. 
This study investigated the diversity of students' use of the tablet, though the quality of the activities prepared by the students for tablet use in the classroom has yet to be examined. It is thus recommended to analyze the lesson plans and activities, as well as the levels of thinking required of learners in classes where the tablet is integrated.

\section{References}

Alexander, B. (2004). Going nomadic: Mobile learning in higher education. Educause Review, 39(5), 6.

Betrus, A. (2012). Linking research and practice to improve learning. TechTrends, 56(5), 42-45

Charmaz, K. (2000). Grounded theory: Objectivist and constructivist methods. In N. Denzin \& Y. S. Lincoln (Eds.), Handbook of qualitative research (2nd ed)., pp. 509-536. Thousand Oaks, CA: Sage.

Chen, G. D., Chang, C. K., \& Wang, C. Y. (2008). Ubiquitous learning website: Scaffold learners by mobile devices with information-aware techniques. Computers and Education, 50, 77-90.

Chen, Y. S., Kao, T. C., \& Sheu, J. P. (2003). A mobile learning system for scaffolding bird watching learning. Journal of Computer Assisted Learning, 19, 347-359.

Cobcroft, R. S., Towers, S., \& Smith, J. (2006). Mobile learning in review: Opportunities and challenges for learners, teachers, and institutions. Proceedings of the Online Learning and Teaching Conference 2006, 21-30.

Dew, J. (2010). Global, mobile, virtual, and social: The college campus of tomorrow. Futurist, 44(2), 4650.

Eagleton, M. \& Dobler, E. (2007). Reading the web: Strategies for internet inquiry. New York \& London: The Guilford Press.

El-Hussein, M. O. M., \& Cronje, J. C. (2010). Defining mobile learning in the higher education landscape. Journal of Educational Technology \& Society, 13(3), 12-21.

Eyal, L. (2012). Digital assessment literacy -- The core role of the teacher in a digital environment. Journal Of Educational Technology \& Society, 15(2), 37-49. Retrieved from: http://www.ifets.info/journals/15_2/5.pdf

Eshet-Alkalai, Y., \& Chajut, E. (2010). You can teach old dogs new tricks: The factors that affect changes over time in digital literacy. Journal of Information Technology Education: Research, 9, 173-181. Retrieved from http://www.jite.org/documents/Vol9/JITEv9p173-181Eshet802.pdf

Fishman, B., Best, S., Marx, R., \&. Tal, T. (2001). Fostering teacher learning in systemic reform: Linking professional development to teacher and student learning. Paper presented at NARST 200.1 St. Louis, MO.

Georgiev, T., Georgieva, E., \& Smrikarov, A. (2004). M-learning - A new stage of e-learning. In International Conference on Computer Systems and Technologies-CompSysTech'2004, Rousse, pp.IV.28, 15.

Herrington, J., Mantei, J., Herrington, A., Olney, I. \& Ferry, B. (2008). New technologies, new pedagogies: Mobile technologies and new ways of teaching and learning. Paper presented at The Australian Society for Computers in Learning in Tertiary Education Conference.

Hutchison, A., Beschorner, B., \& Schmidt-Crawford, D. (2012). Exploring the use of the iPad for literacy learning. The Reading Teacher, 66(1), 15-23.

Jeng, Y. L., Wu, T. T., Huang, Y. M., Tan, Q., \& Yang, S. J. (2010). The add-on impact of mobile applications in learning strategies: A review study. Educational Technology \& Society, 13(3), 3-11.

Johnson, L., Levine, A., Smith, R., \& Stone, S. (2010). The 2010 Horizon Report. Austin, TX: The New Media Consortium. 
Kelly, J., \& Schrape, J. (2010). 100 days with an iPad: Lessons learnt and apps acquired. Poster presented at the Australian Society for Computers in Learning in Tertiary Education Conference (ASCILITE) Proceedings. AU: Sydney.

Larson, L.C. (2010). Digital readers: The next chapter in e-book reading and response. The Reading Teacher, 64(1), 15-22.

Lee, J., Luchini, K., Michael, B., Norris, C., \& Soloway, E. (2004). More than just fun and games: Assessing the value of educational video games in the classroom. Proceedings of CHI 2004 Connect: Conference on Human Factors in Computing Systems, Vienna, Austria.

Melhuish, K., \& Falloon, G. (2010). Looking to the future: M-learning with the iPad. Computers in New Zealand Schools: Learning, Leading, Technology, 22(3).

Monahan, T., McArdle, G., \& Bertolotto, M. (2008). Virtual reality for collaborative e-learning. Computers \& Education, 50, 1339-1353.

Morrison, M. (2014). Embedding the iPad as a learning and teaching tool: A case study of staff and student perspectives in a Management School. Proceedings of the First International Conference on the use of iPads in Higher Education 2014, 20th, 21st, 22nd March 2014, Paphos. Retrieved from: www.ipadsinhe.org

Mouza, C. (2008). Learning with laptops: Implementation and outcomes in an urban, under-privileged school. Journal of Research on Technology in Education, 40(4), 447-473.

Naismith, L., Sharples, M., Vavoula, G., \& Lonsdale, P. (2004). Literature review in mobile technologies and learning. Futurelab series. Harvester Press. Amsterdam and New York: Elsevier.

Peters, K. (2009). M-learning: Positioning educators for a mobile, connected future. In M. Ally (Ed.), Mobile learning: Transforming the delivery of education and training (pp. 113-134). Vancouver: Marquis Book Printing. Retrieved from http://www.aupress.ca/books/120155/ebook/99Z_Mohamed_Ally_2009-MobileLearning.pdf

Price, S., \& Rogers, Y. (2004). Let's get physical: The learning benefits of interacting in digitally augmented physical spaces. Computers \& Education, 43, 137-151

Rosas, R., Nussbaum, M., Cumsille, P., Marianov, V., Correa, M., Flores, P., Grau, V., Lagos, F., Lopez, X., Lopez, V., Rodriguez, P., \& Salinas, M. (2003). Beyond Nintendo: Design and assessment of educational video games for first and second grade students. Computers \& Education, 40(1), 71-94.

Rossing, J. P., Miller, W. M., Cecil, A. K., \& Stamper, S. E. (2012). iLearning: The future of higher education? Student perceptions on learning with mobile Tablets. Journal of the Scholarship of Teaching and Learning, 12(2), 1-26.

Shamir-Inbal, T. \& Blau, A. (2013) Is the technology ripe: Tablets for learning the elementary school. In The Learner in the Technological Era, 8th Chase conference on the research of learning technologies. Open University: Raanana. (in Hebrew).

Speak Up 2010. (2011, April). The new 3 E's of education: Enabled, Engaged, Empowered, How today's students are leveraging emerging technologies for learning. Project Tomorrow. Retrieved from: http://www.tomorrow.org/speakup/pdfs/SU10_3EofEducation_Students.pdf

Tohill, K. (2014). Student teaching with iPads: Incorporating modern digital tools in teacher preparation. Proceedings of the First International Conference on the use of iPads in Higher Education 2014, 20th, 21st, 22nd March 2014, Paphos. Retrieved from: www.ipadsinhe.org

Traxler, J. (2007). Defining, discussing and evaluating mobile learning: The moving finger writes and having writ... The International Review of Research in Open and Distance Learning, 8(2), 1-12.

Traxler, J. (2010). Will student devices deliver innovation, inclusion and transformation? Journal of the Research Centre for Educational Technologies, 6(1), 3-15.

Valentino, D. J. (2010). Using the iPad to connect: Parents, therapists use Apple Tablet to communicate with special needs kids. The Wall Street Journal, Oct. 13, 2010. Retrieved from 
http://online.wsj.com/article/SB10001424052748703440004575547971877769154.html\#articleTabs\% 3Darticle

Wang, K. T., Huang, Y. M., Jeng, Y. L., \& Wang, T. I. (2008). A blog-based dynamic learning map. Computers \& Education, 51(1), 262-278.

Yang, S. J. H. (2006). Context aware ubiquitous learning environments for peer-to-peer collaborative learning. Educational Technology \& Society, 9(1), 188-201.

Zurita, G., Nussbaum, M., \& Salinas, R. (2005). Dynamic Grouping in Collaborative Learning Supported by Wireless Handhelds. Educational Technology \& Society, 8(3), 149-161.

\section{Biography}

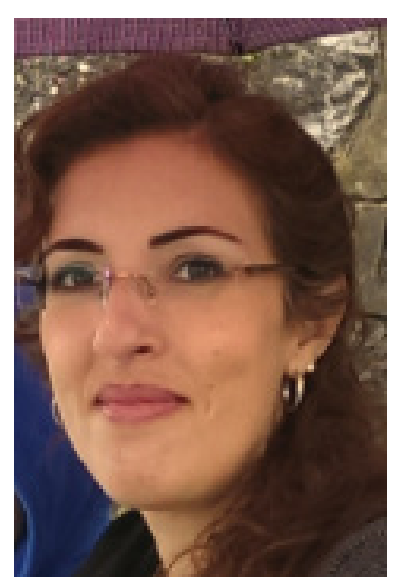

Dr. Eyal is researcher and a faculty member at Levinsky College of Education, Tel-Aviv, and an adjunct professor at The College of Academic Studies, Israel. She holds the Excellence Program coordinator Chair at the R\&D institute for Teacher Education at Levisky College. Dr. Eyal is also an academic consulter for innovative schools at the 'Experiment and Projects' Division at The Ministry of Education in Israel. Areas of her research interests include: Innovative Pedagogy, Learning Technologies, Educational Leadership and Action Research. 